\title{
Der Gute-Nacht-Kuss
}

\section{Lilly Zimmerli-Staub}

Ärztin, 90 Jahre

Vorgetragen anlässlich der ASEM-Lesung in der Pro Senectute in Biel am 7.2. 2015.

Korrespondenz: Lilly Zimmerli-Staub Bolgengasse 29 CH-3770 Zweisimmen
Zuerst will ich mich im Brockhaus orientieren, was sie über den Kuss im Allgemeinen melden. Ich weiss, Google würde mir sicher noch mehr bieten, doch gehöre ich halt noch zur alten Generation, die sich lieber im Brockhaus informiert.

Dort heisst es: «Kuss ist das Berühren eines Menschen oder Gegenstandes mit den Lippen, Bezeugung von Zuneigung und Verehrung, Begrüssung oder Verabschiedung; (Wangenkuss). Erotisch-sexuelle Bedeutung hat der Zungenkuss und symbolisch der Kuss bei Verlöbnis oder Eheschliessung.» Das genügt mir für den Moment.

In den Sinn kommt mir die wunderbare Skulptur von Rodin oder das Bild des Malers Klimt.

Aber was weiss man über den Gute-Nacht-Kuss eines alten Ehepaares?

Man hat den Tag glücklich zusammen beendet, liegt friedlich nebeneinander im gemeinsamen Ehebett. Jedes liest im beleuchteten "Kindle», die Nachttischlämpchen sind gelöscht. Bald legt jeder sein e-Book zur Seite, eines nach rechts, das andere nach links. Und

Es kommt nun darauf an, welche Hüfte weniger schmerzhaft, sondern noch einigermassen beweglich ist.

nun ist der Gute-Nacht-Kuss an der Reihe zum Abschluss des Tages. Ein Kopf dreht sich nach rechts, demjenigen $\mathrm{zu}$, der sich nach links gedreht hat, und beide warten auf den Kuss. Der ist aber in dieser Situation sozusagen noch meilenweit entfernt. Es kommt nun darauf an, welche Hüfte weniger schmerzhaft, sondern noch einigermassen beweglich und fähig ist, sich in die gewünschte Stellung zu bringen. Auch dieses Problem wird nach einigem Hin und Her gelöst, und dem Kuss folgen noch einige liebevolle Streicheleinheiten. Früher war das jeweils eine zarte Aufforderung nach noch mehr Zärtlichkeit, was das Einschlafen

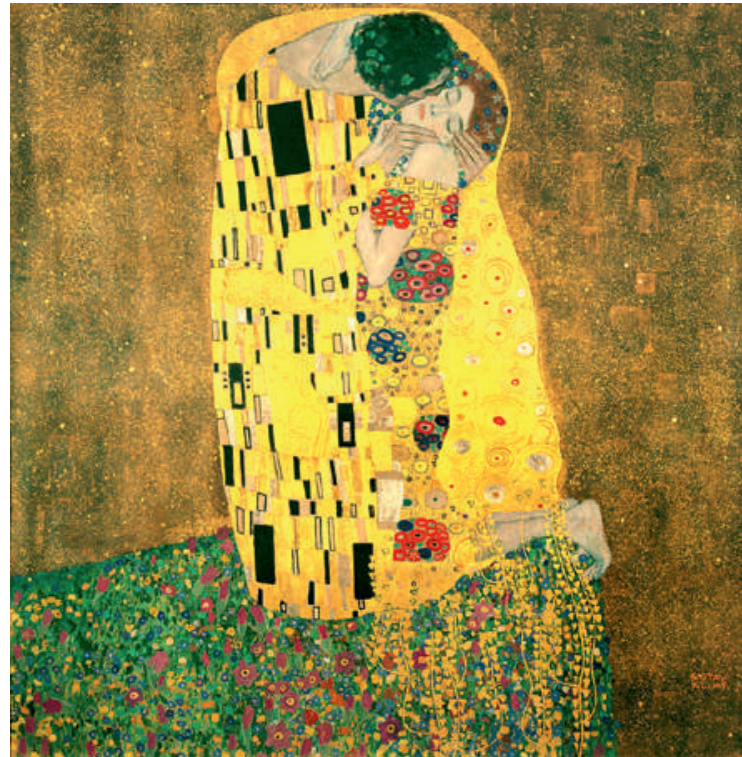

In diesem Alter ist man eben noch biegsam ...

jeweils noch etwas verzögerte. Nun, nach 60 Jahren, sagt der Kuss - ohne wirklich Worte zu benötigen: Schlaf gut, Liebes, schlaf gut, Lieber. Und jeder begibt sich in die gewohnte Schlaflage, und schon bald ertönt von der einen oder anderen Seite her ein heimeliges Schnärcherln oder ein wohliger Atemzug.

Da muss ich gleich ein kleines Gedicht anfügen, das ich meinem Liebsten einmal gewidmet habe:

Die Leidenschaft ist seltsam weit. Es kam die Zeit der Zärtlichkeit.

Doch diese wird mit uns auch älter. Und langsam, langsam etwas kälter. Humor jedoch hat stets noch Platz. Wir hüten ihn wie einen Schatz.

Und dankbar spüren wir was blieb: Wir haben beide uns noch lieb. 